\title{
A comparison of the bactericidal activity of quinolone antibiotics in a Mycobacterium fortuitum model
}

\author{
STEPHEN H. GILLESPIE, IAN MORRISSEY* and DEAN EVERETT \\ Royal Free \& University College Medical School, Royal Free Campus, Rowland Hill Street, London NW3 2PF \\ and * GR Micro Ltd, 7-9 William Road, London NW1 3ER
}

\begin{abstract}
New agents are urgently needed to meet the threat of multiple drug-resistant tuberculosis and to manage infection with the naturally resistant non-tuberculosis mycobacteria. Earlier fluoroquinolones have been shown to have promising in-vitro activity, although mouse infection and clinical studies suggested that they lack sufficient bactericidal activity. Methods were evaluated to measure the bactericidal activity of fluoroquinolones and to compare the new agent moxifloxacin with other fluoroquinolones with M. fortuitum as a model system. The optimum bactericidal concentrations (OBC) for the fluoroquinolones were: moxifloxacin, $0.5 \mathrm{mg} / \mathrm{L}$; ciprofloxacin and sparfloxacin, $2 \mathrm{mg} / \mathrm{L}$ and ofloxacin, $8 \mathrm{mg} / \mathrm{L}$. The bactericidal indices (BI) for moxifloxacin, ciprofloxacin, sparfloxacin and ofloxacin were $1.8,0.5,0.2$ and 0.2 , respectively. Similar ranking was obtained when the time taken to produce one $\log _{10}$ reduction in viable count was calculated. These data indicate that moxifloxacin was the most bactericidal of the fluoroquinolones tested. Such methods provide a simple in-vitro measure that correlates with in-vivo models.
\end{abstract}

\section{Introduction}

Mycobacterial infection is a significant threat to human health and the total number of cases of tuberculosis is rising throughout the world [1]. Multiple drug resistance is also becoming more common and recent outbreaks of multiple drug-resistant tuberculosis among HIV seropositive individuals have been associated with a high mortality and rapid transmission [2]. The incidence of non-tuberculosis mycobacteria is also rising because of an increase in the number of immunocompromised patients, including HIV seropositive individuals, together with improved diagnostic facilities and better understanding of the pathogenesis of these organisms [3].

The fluoroquinolones are a group of potent bactericidal antibacterial agents that target DNA gyrase [4]. Earlier compounds were mainly active against gram-negative pathogens, but the fluoroquinolones, such as ciprofloxacin, had an increased potency against gram-negative pathogens and a wider spectrum that included staphy-

Received 13 Oct. 2000; revised version accepted 4 Dec. 2000.

Corresponding author: Professor S.H. Gillespie (e-mail: stepheng@rfc.ucl.ac.uk). lococci and mycobacteria. Fluoroquinolones have been shown to have anti-mycobacterial activity in vitro $[5,6]$ and mouse models of infection [6,7] show that ciprofloxacin has early bactericidal activity, rapidly reducing the sputum viable count [8]. Clinical trials support the idea that they may have a role to play in the treatment of these infections $[9,10]$.

Developments in the quinolone family have produced agents with enhanced activity against gram-positive organisms and mycobacteria. Studies of substitutions at the C8 position of the quinolone ring suggested that a methoxy group enhanced the anti-mycobacterial activity of quinolones when the position had a cyclopropyl substitution at the N1 position [11, 12]. Moxifloxacin is an 8-methoxyquinolone that is being introduced into clinical practice especially for the treatment of respiratory tract infections. It has enhanced activity against gram-positive pathogens and anaerobes while retaining useful activity against gram-negative organisms [13]. It has been shown to inhibit the growth of the main species of mycobacteria that infect man [14]. Studies of the activity of moxifloxacin in mouse models also suggest that it has important bactericidal activity [7]. Bactericidal activity of antibiotics has been shown to be important early in the course of treatment by ensuring a rapid reduction in the infective load and 
later in killing semi-dormant organisms to sterilise the lesions $[9,15]$. In a controlled trial of a regimen containing ciprofloxacin against standard therapy, patients who were HIV seropositive took longer to achieve sterilisation and had a higher relapse rate [8]. This study suggested that ciprofloxacin lacked sterilising activity in comparison with the standard regimen, and that if quinolone antibiotics are to have a role in anti-tuberculosis therapy, agents with enhanced bactericidal activity must be found. In non-tuberculosis mycobacterial infections, bactericidal activity is essential as these infections often arise in patients with reduced cell-mediated immunity, where little help in eradicating the organism can be expected from the immune system [3].

Most studies of anti-mycobacterial activity of new drugs are reported in the form of the minimal inhibitory concentration (MIC). A more relevant measure of potential usefulness would be in-vitro measures of the bactericidal activity $[8,9,15]$. To develop such a method conventional measures of bactericidal action were adapted to mycobacteria in a Mycobacterium fortuitum model system. The minimum bactericidal concentration (MBC) and the optimum bactericidal concentration (OBC; the most lethal fluoroquinolone concentration over a range of concentrations) were measured. The bactericidal index (BI) was also calculated to relate bactericidal activity with antibiotic concentrations achievable in serum. With this, the bactericidal activity of the new 8-methoxyquinolone was compared with that of older agents and the utility of different measures of bactericidal activity in mycobacteria was evaluated.

\section{Materials and methods}

\section{Drugs and mycobacterial test strain}

The antibacterial agents were obtained from the respective manufacturers. Moxifloxacin (Bayer AG, Wuppertal, Germany) and sparfloxacin (Rhône-Poulenc Santé, France) were dissolved in $0.1 \mathrm{M} \mathrm{NaOH}$ then diluted in sterile distilled water. Ciprofloxacin (Bayer AG) and ofloxacin (Aventis, Romainville, France) were dissolved in sterile distilled water. The test strain for all experiments was M. fortuitum NCTC 10394.

\section{Macrodilution sensitivity testing}

The macrodilution method described previously [16] was used to determine the MIC, which was defined as the lowest concentration at which there was no visible growth. The MBC was defined as the lowest concentration that produced a $99.9 \%$ reduction in viable count. The method was modified by increasing the recommended incubation period to $48 \mathrm{~h}$ and the use of Mueller Hinton Broth (MHB; Mast Diagnostics, Bootle) with Tween 80 (BDH, Poole, Dorset) $0.2 \%$ and albumin dextrose catalase complex (ADC; Becton Dickinson, Oxford) $10 \%$.

\section{Determination of the $O B C$}

Four volumes of $45 \mathrm{ml}$ of MHB with ADC 10\% and Tween $800.2 \%$ were inoculated and incubated for $48 \mathrm{~h}$ at $37^{\circ} \mathrm{C}$, to give an initial inoculum of $10^{7}-10^{8} \mathrm{cfu} / \mathrm{ml}$. The culture was centrifuged at $12000 \mathrm{~g}$ for $1 \mathrm{~min}$ and the supernate was discarded. Pellets were resuspended in $10 \mathrm{ml}$ of MHB containing ADC and Tween. These were transferred into a $250-\mathrm{ml}$ conical flask and the volume was made up to $180 \mathrm{ml}$; 9.9-ml volumes of the inoculum were pipetted into $50-\mathrm{ml}$ conical flasks to give two control flasks and 16 test flasks. To the 16 test flasks, $0.1 \mathrm{ml}$ of the various drug concentrations was added. The concentrations tested were: MIC $\times 0.25$, $\times 0.5, \times 1, \times 2, \times 4, \times 8, \times 16, \times 32$. Sterile distilled water $(0.1 \mathrm{ml})$ was added to each of the control flasks. A $0.1-\mathrm{ml}$ sample from the control flasks was serially diluted to 1 in $10^{5}$ to determine the initial viable count $(\mathrm{t}=0)$. The flasks were incubated on a rotary shaker $(100 \mathrm{rpm})$ at $37^{\circ} \mathrm{C}$ for $6 \mathrm{~h}$, when a second viable count was taken.

To reduce the risk of carry over of antibiotic, the broth cultures were centrifuged and the supernate was discarded before serial dilutions were used to perform viable counts by the Miles and Misra method [17] with duplicate spots of $25 \mu \mathrm{l}$ for dilutions of 1 in $10^{3}$ to 1 in $10^{5}$. The plates were then incubated for $48 \mathrm{~h}$ at $37^{\circ} \mathrm{C}$. The results are expressed as percentage survivors.

\section{$B I$}

The data obtained from viable count studies were reevaluated by calculating the BI as described previously [18]. Briefly, the $\log _{10}$ reduction in cfu was plotted against the $\log _{10}$ concentration of the fluoroquinolone being used. The area under the curve (AUC) for the bactericidal section of each plot was determined and this was defined as the BI for each drug. The highest concentration used for each calculation was the peak serum concentration $\left(\mathrm{C}_{\max }\right)$ as shown in Table 1 $[19,20]$.

\section{Death rates}

The data were also re-calculated to give figures on time taken to achieve one $\log _{10}$ death of $M$. fortuitum against each fluoroquinolone, for each concentration

Table 1. Maximum serum concentration achieved after a single dose for various fluoroquinolones

\begin{tabular}{lcc}
\hline Drug & Single oral dose $(\mathrm{mg})$ & $\mathrm{C}_{\max }(\mathrm{mg} / \mathrm{L})$ \\
\hline Moxifloxacin & 800 & 4.73 \\
Ciprofloxacin & 750 & 3.4 \\
Sparfloxacin & 400 & 2 \\
Ofloxacin & 400 & 7.17 \\
\hline
\end{tabular}


used. This was calculated by a method published previously [21]. Briefly, the formula used to calculate the death rate was $\mathrm{D}=\mathrm{t} / \log _{10} \mathrm{~N}_{0}-\log _{10} \mathrm{~N}_{\mathrm{t}}$; where $\mathrm{D}=$ the death rate, $\mathrm{t}=$ the relevant time, $\mathrm{N}_{0}$ is the initial viable count at $t=0$ and $N_{t}$ is the viable count at $\mathrm{t}$.

\section{Results}

\section{Macrodilution MIC and MBC}

The susceptibility of $M$. fortuitum to the fluoroquinolones as defined by MIC and MBC is shown in Table 2. The modal values were determined from six experiments.

\section{$O B C$}

The results expressed graphically in Fig. 1 are averages of six experiments for each fluoroquinolone after incubation for $6 \mathrm{~h}$. The $\mathrm{OBCs}$ were calculated from the plots as follows: moxifloxacin $0.5 \mathrm{mg} / \mathrm{L}$, ciprofloxacin and sparfloxacin $2 \mathrm{mg} / \mathrm{L}$ and ofloxacin $8 \mathrm{mg} / \mathrm{L}$. Results from 16-h investigations (data not shown) gave no clearly defined $\mathrm{OBC}$ as all concentrations exhibited a $>99 \%$ drop in $\mathrm{cfu} / \mathrm{ml}$.

Table 2. Comparison of the MIC and MBC of fluoroquinolones against $M$. fortuitum

\begin{tabular}{lccc}
\hline Drug & $\begin{array}{c}\text { Modal MIC } \\
(\mathrm{mg} / \mathrm{L})\end{array}$ & $\begin{array}{c}\text { Modal MBC } \\
(\mathrm{mg} / \mathrm{L}\end{array}$ & $\begin{array}{c}\text { MIC/MBC } \\
\text { ratio }\end{array}$ \\
\hline Moxifloxacin & 0.12 & 0.25 & 2 \\
Ciprofloxacin & 0.25 & 0.5 & 2 \\
Sparfloxacin & 0.25 & 0.5 & 2 \\
Ofloxacin & 2 & 4 & 2 \\
\hline
\end{tabular}

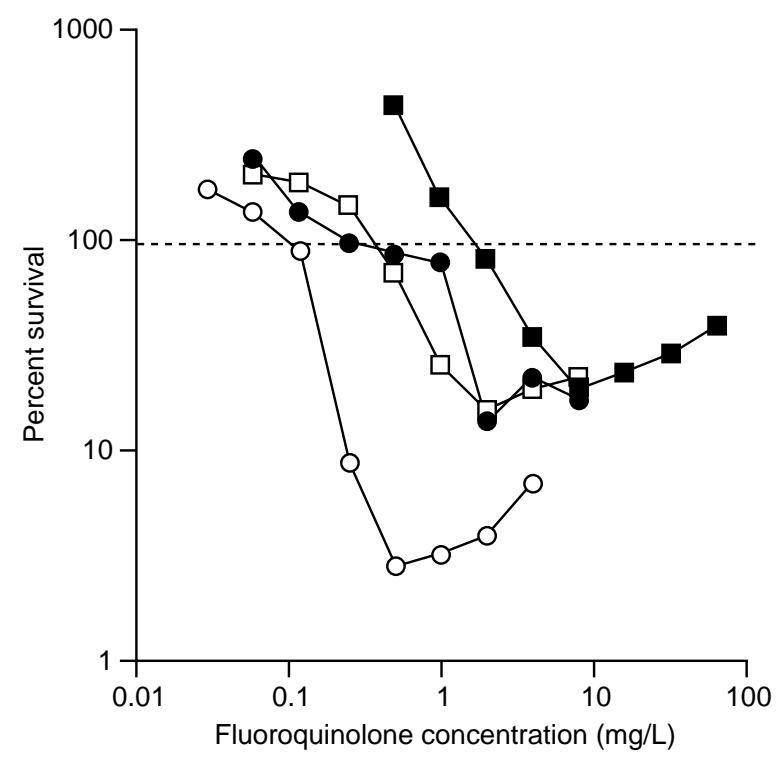

Fig. 1. The OBC plots for moxifloxacin (O), sparfloxacin $(\bullet)$, ciprofloxacin $(\square)$ and ofloxacin (ロ) over 6 h. Data points represent the mean of six observations.

\section{$B I$}

Fig. 2 shows plots of the $\log _{10}$ reduction in viability against the $\log _{10}$ of the drug concentration after $6 \mathrm{~h}$. The $\log _{10}$ reduction values for $\mathrm{C}_{\max }$ were taken from Table 1. This was the cut-off point for AUC calculations as shown in Fig. 2. The BIs were calculated to be 1.8 for moxifloxacin, 0.5 for ciprofloxacin, 0.2 for sparfloxacin and 0.2 for ofloxacin.

\section{Death rates}

The results are presented in Table 3 and these correspond to the time the concentrations would take to produce one $\log _{10}$ death at differing concentrations.

\section{Discussion}

The results clearly show that the fluoroquinolones used in this investigation were all bactericidal with $\mathrm{MIC} /$ $\mathrm{MBC}$ ratios of 2. MIC and $\mathrm{MBC}$ results for three of the fluoroquinolones were similar to those published previously [22]. With this method of evaluation, the activity of moxifloxacin is similar to the older compounds.

The biphasic nature of quinolone action described in other organisms was less marked in these experiments with the exception of ciprofloxacin, which gave the most clearly defined OBC. It has been proposed that the biphasic nature of fluoroquinolone bactericidal profiles is a consequence of inhibition of RNA synthesis at high fluoroquinolone concentration [23, 24]. This is thought to occur because fluoroquinolones require RNA synthesis for full bactericidal activity; therefore, this biphasic phenomenon is due to selfantagonism. Fluoroquinolones vary in their reliance on RNA synthesis for killing. Older quinolones such as nalidixic acid are devoid of bactericidal activity if RNA synthesis is inhibited, because they can kill only by the mechanism classified as type A [24]. On the other hand, newer quinolones can still exert bactericidal activity under RNA synthesis inhibition if they possess the type $\mathrm{B}$ and $\mathrm{B}_{1}$ bactericidal mechanism [24]. However, the action of ciprofloxacin against $M$. smegmatis and $M$. bovis BCG could be partially blocked by pre-treatment with chloramphenicol, a potent inhibitor of protein synthesis [25]. It was also blocked by very high concentrations of ciprofloxacin, as in the present study. Recently, it has been shown that with increasing concentrations of ciprofloxacin, there is a shift from a chloramphenicol-inhibited to chloramphenicol-insensitive mode of killing [26] and it is thought unlikely that inhibition of RNA synthesis would affect a process independently of protein synthesis. The data presented in Fig. 1 shows a weak biphasic pattern, suggesting that moxifloxacin, sparfloxacin and ofloxacin exhibit type B killing against $M$. fortuitum. Ciprofloxacin may exert its bactericidal 


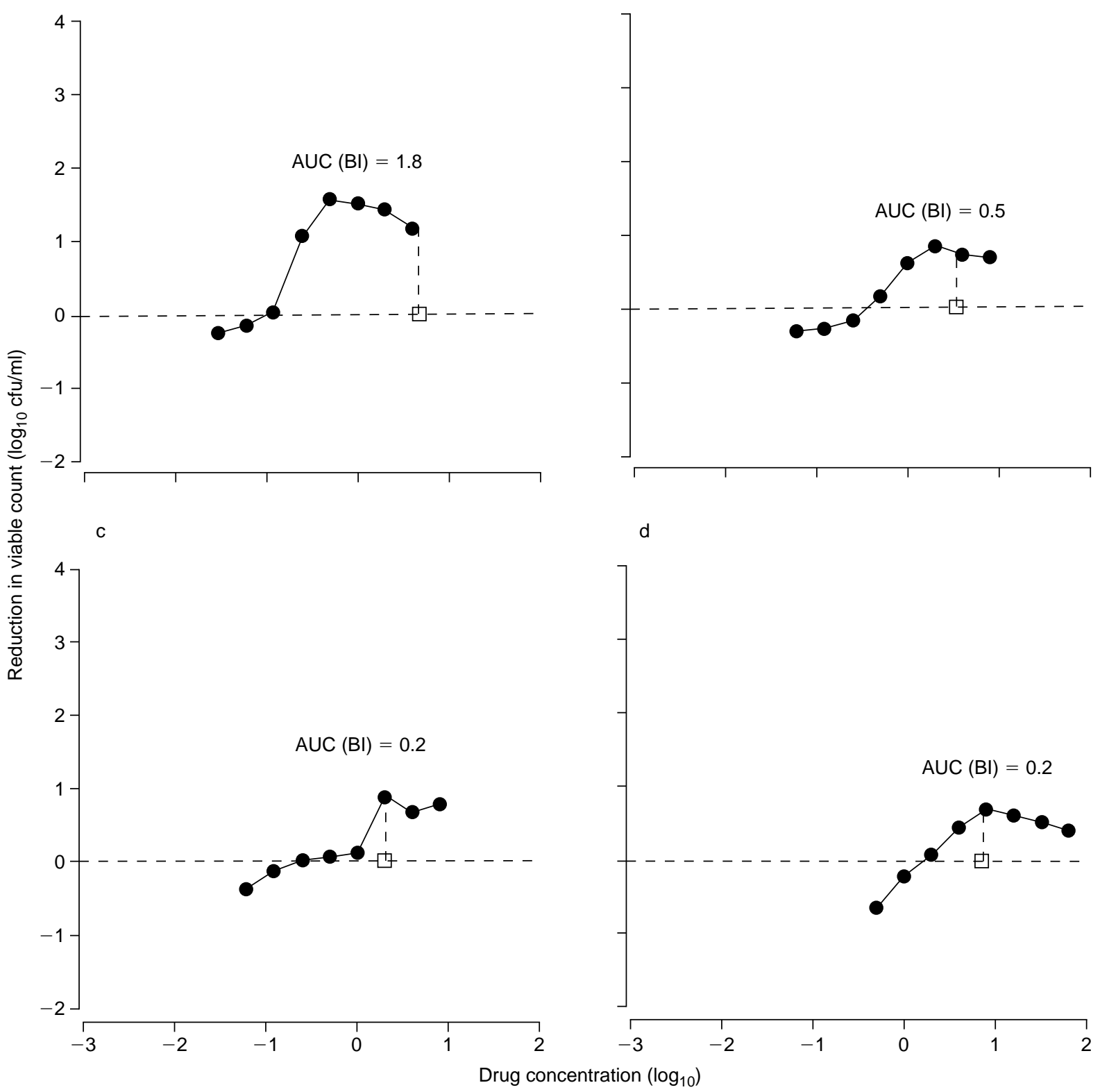

Fig. 2. Plots of the $\log _{10}$ reduction in cfu against the $\log _{10}$ of drug concentration for moxifloxacin (a), ciprofloxacin (b), sparfloxacin (c) and ofloxacin (d). The data points represent the mean of six observations. AUCs were determined for the region of each plot dissected by the vertical and horizontal dotted lines, which are the $\log _{10} \mathrm{C}_{\max }$ and bacteristatic point, respectively.

Table 3. Comparison of the rate of killing (death rate) for four fluoroquinolones against $M$. fortuitum

\begin{tabular}{|c|c|c|c|c|}
\hline \multirow{2}{*}{$\begin{array}{l}\text { Antibiotic } \\
\text { concentration } \\
(\mathrm{mg} / \mathrm{L})\end{array}$} & \multicolumn{4}{|c|}{ Time (h) to produce one $\log _{10}$ reduction in viable count with } \\
\hline & moxifloxacin & ciprofloxacin & sparfloxacin & ofloxacin \\
\hline 0.12 & 200 & ND & ND & ND \\
\hline 0.25 & 2.9 & 300 & ND & ND \\
\hline 0.5 & 3.9 & 5.7 & 46.2 & ND \\
\hline 1.0 & 4.1 & 5.3 & 11.5 & ND \\
\hline 2.0 & 4.4 & 7.9 & 7.9 & 66.7 \\
\hline 4.0 & 5.6 & 12 & 9.4 & 15.4 \\
\hline 8.0 & ND & 7.5 & 8.7 & 9.5 \\
\hline 16.0 & ND & ND & ND & 10.9 \\
\hline 32.0 & ND & ND & ND & 13.4 \\
\hline 64.0 & ND & ND & ND & 13.6 \\
\hline
\end{tabular}

ND, not determined. 
activity by a type A mechanism because the biphasic nature of the response is more pronounced. Furthermore, as the OBCs became less pronounced at $16 \mathrm{~h}$ compared with $6 \mathrm{~h}$, this suggests that mechanisms B or B1 may act more slowly than mechanism A against $M$. fortuitum. Further studies are required to evaluate this more fully.

It has been suggested previously that the potency of the fluoroquinolones can be compared by reference to the OBC value measured after $6 \mathrm{~h}$ [23]. This method was adapted for use in mycobacteria. The data indicate that moxifloxacin has the lowest $\mathrm{OBC}$ value $(0.5 \mathrm{mg} / \mathrm{L})$, suggesting that it is more bactericidal than the comparitors sparfloxacin $(2 \mathrm{mg} / \mathrm{L})$, ciprofloxacin $(2 \mathrm{mg} / \mathrm{L})$ and ofloxacin $(8 \mathrm{mg} / \mathrm{L})$. After $16 \mathrm{~h},>99 \%$ of the bacteria were killed by all of the fluoroquinolones with no discernable difference in the OBC. This difference may be important when the plasma half-lives of the drugs are taken into consideration. If the fluoroquinolone possesses a short half-life, the $\mathrm{OBC}$ is an important factor because the optimum kill rate would be desirable, if time were limited. However, if the fluoroquinolone possessed a long half-life the OBC would be less relevant. The drug would persist for longer, thereby allowing more time for bactericidal killing to occur. This could have a direct relevance to once-daily dosing in tuberculosis regimens, thereby allowing for a more manageable drug course to be administered, which would aid patient compliance.

The results show that moxifloxacin was approximately twice as bactericidal as ciprofloxacin and almost 10 times more bactericidal than both sparfloxacin and ofloxacin as defined by BI. Ciprofloxacin and sparfloxacin were more active than ofloxacin and ciprofloxacin was more bactericidal than sparfloxacin. The low AUC value and correspondingly low bactericidal area displayed by sparfloxacin ( 0.3$)$ may be due to the fact that this fluoroquinolone is widely distributed into the tissues of the patient, rather than remaining in the serum [27]. The analysis of killing rates concurred with the BI data indicating that moxifloxacin is more bactericidal than the other fluoroquinolones tested.

This study adapted previously described methods of determining $\mathrm{OBC}$, death rates and $\mathrm{BI}$ to use with mycobacteria. The results suggest that this approach is valuable and correlates well with in-vivo studies that show that moxifloxacin is more bactericidal than sparfloxacin [7]. If a conventional MIC/MBC approach had been used, the superior bactericidal activity of moxifloxacin over sparfloxacin would not have been demonstrated.

In conclusion, with the incidence of drug-sensitive and drug-resistant tuberculosis steadily increasing on a global scale, moxifloxacin shows a great deal of promise in the future management of mycobacterial infections. New quinolones with potential activity against mycobacteria should be tested in vitro by the methods described in this paper, as this will provide a more accurate measure of bactericidal activity. Further study of the bactericidal activity of fluoroquinolnes are required in $M$. tuberculosis and other slow-growing species and this will allow the most promising new agents to be selected for clinical studies.

This study was supported by a grant from Bayer AG. We thank Professor Jeremy Hamilton-Miller for his critical reading of the manuscript and Therese Donnelly for secretarial assistance.

\section{References}

1. Pablos-Méndez A, Raviglione MC, Laszlo A et al. Global surveillance for antituberculosis-drug resistance, 1994-1997. World Health Organization, International Union against Tuberculosis and Lung Disease Working Group on Anti-Tuberculosis Drug Resistance Surveillance. $N$ Engl J Med 1998; 338: 1641-1649.

2. Fischl MA, Uttamchandani RB, Diakos GL et al. An outbreak of tuberculosis caused by multiple-drug-resistant tubercle bacilli among patients with HIV infection. Ann Intern Med 1992; 117: 177-183.

3. Gillespie SH. Non-tuberculosis mycobacteria. In: Emmerson AM, Hawkey PM, Gillespie SH (eds) Principles and practice of clinical bacteriology. Chichester, John Wiley and Sons. 1997: 239-250

4. Drlica K, Zhao X. DNA gyrase, topoisomerase IV, and the 4quinolones. Microbiol Mol Biol Rev 1997; 61: 377-392.

5. Garcia-Rodriguez JA, Gomez Garcia AC. In-vitro activities of quinolones against mycobacteria. $J$ Antimicrob Chemother 1993; 32: 797-808.

6. Ji B, Lounis N, Truffot-Pernot C, Grosset J. In vitro and in vivo activities of levofloxacin against Mycobacterium tuberculosis. Antimicrob Agents Chemother 1995; 39: 1341-1344.

7. Miyazaki E, Miyazaki M, Chen JM, Chaisson RE, Bishai WR. Moxifloxacin (BAY 12-8039), a new 8-methoxyquinolone, is active in a mouse model of tuberculosis. Antimicrob Agents Chemother 1998; 43: 85-89.

8. Kennedy N, Fox R, Kisyombe GM et al. Early bactericidal and sterilising activities of ciprofloxacin in pulmonary tuberculosis. Am Rev Respir Dis 1993; 148: 1547-1551.

9. Kennedy N, Berger L, Curram J et al. Randomized controlled trial of a drug regimen that includes ciprofloxacin for the treatment of pulmonary tuberculosis. Clin Infect Dis 1996; 22: $827-833$.

10. Gillespie SH, Kennedy N. Fluoroquinolones: a new treatment for tuberculosis? Int J Tuberc Lung Dis 1998; 2: 265-271.

11. Renau TE, Gage JW, Dever JA et al. Structure-activity relationships of quinolone agents against mycobacteria: effect of structural modification at the 8 position. Antimicrob Agents Chemother 1996; 40: 2363-2368.

12. Renau TE, Snachez JP, Gage JW et al. Structure-activity relationships of the quinolone antibacterials against mycobacteria: effect of structural changes at N-1 and C-7. J Med Chem 1996; 39: 729-735.

13. Woodcock JM, Andrews JM, Boswell FJ, Brenwald NP, Wise R. In-vitro activity of BAY 12-8039, a new fluoroquinolone. Antimicrob Agents Chemother 1997; 41: 101-106.

14. Gillespie SH, Billington O. Activity of moxifloxacin against mycobacteria. J Antimicrob Chemother 1999; 44: 393-395.

15. Mitchison DA. The action of antituberculosis drugs in shortcourse chemotherapy. Tubercle 1985; 66: 219-225.

16. Heifets L. Susceptibility testing of Mycobacterium avium complex isolates. Antimicrob Agents Chemother 1996; 40: 1759-1767.

17. Miles AA, Misra SS. The estimation of the bactericidal power of the blood. J Hyg 1938; 38: 732-748.

18. George J, Morrissey I. The bactericidal activity of levofloxacin compared with ofloxacin, D-ofloxacin, sparfloxacin and cefotaxime against Streptococcus pneumoniae. J Antimicrob Chemother 1997; 39: 719-723.

19. Stass H, Dalhoff A, Kubitza D, Schühly U. Pharmacokinetics, safety, and tolerability of ascending single doses of moxiflox- 
acin, a new 8-methoxy quinolone, administered to healthy subjects. Antimicrob Agents Chemother 1998; 42: 2060-2065.

20. Bergan T. Pharmacokinetics of fluorinated quinolones. In: Andriole VT (ed) The quinolones. London, Academic Press. 1988: 119-154.

21. MacGowan AP, Wooton M, Hedges AJ, Bowker KE, Holt HA, Reeves DS. A new time-kill method of assessing the relative efficacy of antimicrobial agents alone and in combination developed using a representative $\beta$-lactam, aminoglycoside and fluoroquinolone. J Antimicrob Chemother 1996; 38: 193-203.

22. Hernandez AM, Arias A, Felipe A, Alvarez R, Sierra A Determination of the susceptibility in vitro of 54 isolates of Mycobacterium fortuitum against three fluoroquinolones using two methods. $J$ Chemother 1995; 7: 109-113.

23. Smith JT, Lewin CS. Chemistry and mechanisms of action of the quinolone antibacterials. In: Andriole VT (ed) The quinolones. London, Academic Press. 1988: 23-82.

24. Lewin CS, Morrissey I, Smith JT. The mode of action of the quinolones: the paradox in activity of low and high concentrations and in the activity in the anaerobic environment. Eur J Clin Microbiol Infect Dis 1991; 10: 240-248.

25. Drlica $\mathrm{K}, \mathrm{Xu} \mathrm{C}$, Wang J-Y, Burger RM, Malik $M$ Fluoroquinolone action in mycobacteria: similarity with effects in Escherichia coli and detection by cell lysate viscosity. Antimicrob Agents Chemother 1996; 40: 1594-1599.

26. Chen C-R, Malik M, Snyder M, Drlica K. DNA gyrase and topoisomerase IV on the bacterial chromosome quinoloneinduced DNA cleavage. J Mol Biol 1996; 258: 627-637.

27. Goa KL, Bryson HM, Markham A. Sparfloxacin. A review of its antibacterial activity, pharmacokinetic properties, clinical efficacy and tolerability in lower respiratory tract infections. Drugs 1997; 53: 700-725. 